\title{
Students' Academic Difficulties in Learning a Statistics and Probability Course: The Instructors' View
}

\author{
Dr. Refat Abdelsamad Abouelgheat Kandeel \\ Associate Professor \\ Correspondence: Basic Science Department, Common First Year (CFY), King Saud University, Saudi Arabia
}

\begin{abstract}
The purpose of this study is to determine students' academic difficulties in learning a statistics and probability course. The study sample consisted of 24 instructors (male and female) in the Humanities track in the Department of Basic Sciences in the Common First Year (CFY) at King Saud University (KSU). The results showed that students in the Humanities track faced several academic difficulties in learning statistics and probability and these difficulties were concentrated in the lessons of permutation, combination, probability and random variables. The results indicated that all the difficulties that instructors surveyed occurred at a high or very high level and that no single difficulty was located at the medium or lower levels. The results indicated that, from the point of view of the instructors, there were no statistically significant differences in the level of students' academic difficulties in learning statistics and probability related to the type of instructor (male or female), the instructor's experience in the CFY (less than five years, over or equal to five years), and specialization (statistics, mathematics).
\end{abstract}

Keywords: Students' Difficulties, Mathematics' Difficulties, Statistics and Probability.

DOI: $10.7176 / \mathrm{JEP} / 10-9-05$

Publication date:March $31^{\text {st }} 2019$

\section{Introduction and Theoretical Framework}

\subsection{Introduce the Problem}

Mathematics is one of the most important subjects of our time. All other sciences are based on it. In addition, its abstract thinking transforms the world into symbols and symbolic relationships. Mathematics is the basis for the advancement of human thought, including philosophical thought. The progress of humankind and the scientific revolution of recent years on Earth and space from the application of mathematical relations and equations.

This is consistent with Acharya (2017), who stressed that mathematics is one of the most important subjects in human life. Without mathematics, we can say that nothing is possible in the world. Today, mathematics is globally accepted, but locally useless. Mathematics has been accepted as an important component of formal education from the ancient period to the present day. In the ancient period, great shepherds developed mathematics. Mathematics is a body of knowledge in the area of science and technology. It is beautiful and interesting because of its symbols, language, terms, technology, etc. Mathematics represents a key feature of the human lifestyle. Throughout the world, different countries and regions (like China, America, Japan, and Arabia) have their own mathematical languages, terms, symbols, and counting systems. Mathematics has many branches, some of which serve specific fields in other sciences in particular, and in life in general. Such fields include statistics and probability. Mendoza (1999) emphasized that the statistical education will be more important in the 21 st century. It has a close connection to other sciences and various life situations (Elmaneay, 2016).

The statistics used in the field of mathematics, and in every field to discern the present situation and make correct decisions as a means of adapting to a developing and changing world (Koparan, 2015).

The teaching of statistics is currently increasing substantially in many countries, due to its widely recognized place in the general education of citizens. Some countries have put much effort into designing curricula and specific materials, for example, those produced for the Schools Council Project on Statistical Education in England, and The Quantitative Literacy Project in the US. The increasing interest in teaching statistics is also shown by the existence of specific journals and regular international conferences, an ongoing series of roundtable conferences promoted by the ISI, and the formation in 1992 of an international association, IASE (International Association for Statistical Education). The establishment of Centers for Statistical Education in England, Italy, and the US also demonstrates this interest. The greater emphasis placed on statistics in the NCTM Standards in the US, the Mathematics National Curriculum in England and Wales, and the new Spanish curricular proposal all require an intensive preparation of teachers so that they can accomplish their educational goals. Many teachers must increase their knowledge of both the subject matter of statistics and appropriate ways to teach the subject (Batanero, Godino, Vallecillos, Green, \& Holmes, 1994).

For five years, a group of mathematics and statistics educators worked in collaboration to reflect on the teaching of statistics in school mathematics and on the training of those teachers responsible for this teaching, under the auspices of the International Commission on Mathematical Instruction (ICMI) and the International Association for Statistical Education (IASE). Results from this work are reflected first in the Proceedings of the Joint ICMI/IASE Study Conference held in Monterrey in 2008 (Batanero, Burrill, Reading, \& Rossman, 2008), 
and second in this book. These two documents have helped raise awareness of the need for increased statistical content at various school levels to improve statistical literacy in young students around the world, as well as awareness of the related challenges in training and supporting mathematics teachers who provide instruction in statistics (Batanero, Burrill, \& Reading, 2011).

Despite the widespread emphasis on reform in the teaching of statistics and the increase in the number of papers about statistics education in the research literature, statistics is still regarded as a discipline requiring significant improvement in terms of how students are educated. Over the past few decades, researchers and educators have sought to understand the challenges in learning and teaching statistics and to identify the changes necessary for training future statisticians. However, it seems that a gap still exists between the research and practice of teaching statistics. Not all statisticians are aware of the full learning potential of their discipline, which can be reached by research-based strategies. (Tishkovskaya \& Lancaster, 2012).

Learning difficulties are generally areas that have only recently attracted the attention of education professionals, with interest growing from the second half of the twentieth century. This attention is increasing markedly from year to year. The problem involves a large number of students; their difficulties appear in late childhood, mainly in academic education (Alshakhs, 2006). Mathematics learning difficulties are the most common learning difficulties among primary, preparatory, and secondary students, and even university students. The prevalence of these difficulties changes with such variables as cultural, economic, and social levels, as well as gender. Although difficulties in learning math, statistics, and probability are significant, they often do not receive attention until relatively late. Most of the research and studies focus on reading and writing difficulties; few of them focus on the difficulties involved in learning mathematics and its various branches (Elmaneay, 2016). The difficulties that students face when learning mathematics are not focused on one particular branch of mathematics, but rather in all branches. Many researchers have done various studies in different branches of mathematics. These studies show that students suffer from many difficulties in mathematics.

Tall and Razali (1993) study considers the results of a diagnostic test of student difficulty and contrasts the difference in performance between the lower attaining quartile and the higher quartile. It illustrates a difference in qualitative thinking between those who succeed and those who fail in mathematics, illustrating a theory that those who fail are performing a more difficult type of mathematics (coordinating procedures) than those who succeed (manipulating concepts). Students who have to coordinate or reverse processes in time will encounter far greater difficulty than those who can manipulate symbols in a flexible way.

Zachariades, Christou, and Papageorgiou (2001) investigated the difficulty levels of the identification of functions in different representations of mathematical relations. The relative difficulties associated with functions and developmental levels were examined using a written test administered to 38 first-year undergraduate students. The results appeared to support the assumption that a developmental pattern in students' thinking identifies functions based on their symbolic and graphical forms.

Bryant, Bryant, Kethley, Kim, Pool, and Seo (2008) study examined lessons from kindergarten and first- and second- grade basal mathematics textbooks to determine the extent to which 11 critical features of instruction were present. Overall, results showed an "Approaching Acceptable" rating, meaning that the features were not fully incorporated. Implications include the need for textbook adoption committees to be mindful of the importance of including effective instructional practices when making textbook decisions and for teachers to scrutinize the components of lessons to determine if these features of effective instruction are included.

Bryant, Bryant, Gersten, Scammacca and Chavez (2008) sought to examine the effects of Tier 2 intervention in a multitiered model on the performance of first- and second grade students who were identified as having mathematics difficulties. A regression discontinuity design was utilized. The participants included 126 (Tier 2, n $=26$ ) first graders and 140 (Tier 2, $\mathrm{n}=25$ ) second graders. Tier 2 students received 15- min intervention booster lessons for 18 weeks in early mathematics skills and concepts. Results showed a significant intervention effect for second-grade Tier 2 students on the Texas Early Mathematics Inventories-Progress Monitoring (TEMI-PM) total standard score. The effect was not significant for first-grade Tier 2 students.

Hudson, Kadan, Lavin and Vasquez (2010) confirmed in their study that the students of the targeted fourth, fifth, sixth, and ninth grade classes exhibited difficulties with number sense that interfered with an understanding and recall of basic math facts. Evidence for the existences of the problem included teacher observation, test scores, and student and teacher surveys. The research participants included 42 children under 12 years old, 50 children over 12 years old and 20 teachers. The dates of the study were January 11, 2010 - May 07, 2010. During the course of this intervention, teacher researcher(s) attempted to enhance students' basic math skills by re-teaching basic math skills with an emphasis on number sense using computers, calculators, and other technological devices. The students accessed mathematical websites and software via computers weekly. The rationale for the action research project was to enhance basic math skills of the targeted fourth, fifth, sixth, and ninth graders. Deficiencies in basic math skills in the classroom typically lead to inaccurate computation that created obstacles when problem solving. After a thorough review of the literature, three common probable causes were found to be lack of prior knowledge, negative attitude towards math, varied teaching methods. After a review of the literature, the teacher researchers 
selected four possible solutions for the lack of retention of basic math skills from the variety of solutions proposed by researchers. These possible solution strategies included early screening, implementing the use of manipulatives, cooperative learning, and integrating technology. The teacher researchers recommend that all mathematics teachers, regardless of grade level, take some time to reinforce basic math skills. To reinforce and explore these topics, the teacher researchers recommend using technology such as software programs, PowerPoint, Elmos, Smart Boards, projectors, calculators, internet websites, YouTube videos and DVDs, and music CDs. Overall, targeted students in the fourth, fifth, sixth, and ninth grades improved their understanding of basic math skills by using technology. Their post intervention test scores indicated a noticeable increase in student mastery of basic mathematics. More students earned scores of $70 \%$ or higher when compared to the pre assessment scores.

The focus of Tambychik and Meera's (2010) study was on discussing the major mathematics skills and cognitive abilities in learning that caused difficulties in mathematics problem solving among students from the students' points of view. The study was carried out on three focus group samples selected using a purposeful sampling approach. A mixed qualitative and quantitative approach was used to create a clearer understanding. In addition to the questionnaire, focus group interviews were carried out. The researchers recorded and copied interviews, then analyzed the data descriptively. Data findings showed that respondents lacked many mathematics skills such as number-fact, visual-spatial, and information skills. Information skills were the most critical. The deficiency of these mathematics skills and cognitive abilities in learning inhibits mathematical problem-solving. This understanding of how deficits influence problem solving is expected to provide effective guidelines in preparing diagnostic instruments and learning modules to develop mathematics skills.

Grehan, O'shea and Bhai (2010) sought to determine why students do or do not engage with mathematics support. Initial interviews were conducted with students who had failed first year. This study gives preliminary findings from interviews with a second group of students who had passed first year. Students were chosen who had similar mathematical backgrounds to the first group and who had all engaged with mathematics. The students' mathematical backgrounds do not appear to be the only major factor in determining engagement. We found that both groups experienced similar difficulties and problems.

The study of Pepper, Chasteen, Pollock, and Perkins (2012) discussed common difficulties in upper-division's electricity and magnetism (E\&M) in the areas of Gauss's law, vector calculus, and electric potential using both quantitative and qualitative evidence. It also showed that many of these topical difficulties might be tied to student difficulties with mathematics. At the junior level, some students struggle to combine mathematical calculations and physics ideas, to account for the underlying spatial situation when doing a mathematical calculation, and to access appropriate mathematical tools.

An overarching question guided Vokovic's (2012) study: What is the mathematical difficulty (MD) independent of reading difficulty (RD)? The sample included 203 children whom the researchers followed from kindergarten to third grade. The researchers used latent growth modeling to investigate the relationship between the MD and measures of working memory, short-term memory, cognitive processing speed, early numerical skills, and phonological processing, independent of reading. Two main findings emerged: (a) deficits in early numerical skills were a defining feature of MD with or without RD, and (b) early numerical skills and phonological processing influenced growth in mathematics from kindergarten to third grade. These results indicate that future MD research should focus on numerical and language-based skills, including whether the mathematics disorder is MD-specific or otherwise reflects underlying language and/or numerical deficits.

Asha, Beqe'e, and Alabsi's (2014) study investigated the perspectives of Practicum Students (PS) on the levels of difficulties that confronted their pupils, who were learning mathematics. The researchers also examined PS suggestions to overcome such difficulties. The study sample included 101 practicum students trained to be class teachers at the UNRWA College of Educational Sciences and Arts. To achieve the study objectives, the researchers designed and administered a scale comprising 38 items, which were grouped into three areas, each of which integrated a number of sub-items: curriculum (12 items), teacher (10 items), and student (16 items). The results revealed mid-level difficulties in learning mathematics in the three areas; in descending order, they were a student, teacher, and curriculum. In terms of GPA variables, the results showed no statistically significant differences in defining the level of difficulties to learn mathematics as seen by Practicum Students, who suggested the implementation of specialized educational programs and the use of diverse teaching/learning strategies to overcome such difficulties.

While Jupri and Drijvers (2016) sought to investigate student difficulties in solving word problems in algebra, a teaching experiment involving 51 Indonesian students (12- and 13-year-olds) who used a digital mathematics environment. The findings backed up by an interview study involving 80 students (13- and 14-year-olds). The activity to transform a problem into a symbolic mathematical problem and to reorganize the mathematical system was used to identify student's difficulties on the topic of linear equations in one variable. The results showed that forming a mathematical model - evidenced by errors in formatting equations, schemas, or diagrams - was the main difficulty. This highlights the importance of mathematics as a critical process in the learning and teaching of algebra. 
Acharya (2017) explored the adversities that public school students face in learning mathematics in their learning context. The main purpose of this study was to explore the causes of learning difficulties in mathematics. The study's design was qualitative in nature. Classroom observations / practices of three schools in the Arghakhanchi district and interview taken by the research participants to achieve the research objective. It discussed the different data texts from the potential participants. Analysis and interpretation of data produced the conclusion that students, teachers, and parents play important roles as providers of a sound environment for the improvement of the pass rate. The main causes of difficulties in learning mathematics are as follows: a teacher's failure to link a new mathematical concept to the previously learned mathematical structure, mathematics anxiety, negative feelings about mathematics, economic conditions, educational backgrounds, the school management system, a lack of infrastructure in the school, and a lack of a regular assessment system in the school.

Holm, Aunio, Bjorn, Klenberg, Korhonen, and Hannula (2017) investigated behavioral executive functions (EFs) in the mathematics classroom context among adolescents with varying mathematics performance levels. Using a behavioral rating inventory, teachers assessed EF problems. By cutoff scores on a standardized mathematics assessment, groups with mathematics difficulties (MD; $n=124)$, low mathematics performance (LA; $\mathrm{n}=140$ ), and average or higher scores ( $\mathrm{AC} ; \mathrm{n}=355)$ were identified. The results showed that the MD group had more problems with distractibility, directing attention, shifting attention, initiative, execution of action, planning, and evaluation than did the LA group, whereas the differences in hyperactivity, impulsivity, and sustaining attention were not significant. Compared to the AC group, the MD group showed more problems with all behavioral EFs except hyperactivity and impulsivity, while the LA group showed more problems only with shifting attention. Male adolescents showed more behavioral EF problems than did female adolescents, but a gender difference was negligible within the MD group.

In the field of statistics and probability, Batanero, Godino, Vallecillos, Green and Holmes (1994) presented a survey of the reported research about students' errors, difficulties and conceptions concerning elementary statistical concepts. Information related to the learning processes is essential to curricular design in this branch of mathematics. In particular, the identification of students' errors and difficulties was important to organize statistical training programs and to prepare didactical situations, which allow the students to overcome their cognitive obstacles. This study did not attempt to report on probability concepts, an area that has received much attention, but concentrates on other statistical concepts, which have received little attention hitherto.

Lee and Mavrotheris (2003) attempted to address a concern about students having a poor understanding of one of the most commonly used graphical tools: the histogram. We developed four test items designed specifically to investigate the students' reasoning about histograms, and analyzed 162 students' responses to these items. Based on this analysis, we have identified four main types of student difficulties in constructing, interpreting, and applying histograms in different real-world contexts:

1. Perceiving histograms as displays of raw data with each bar standing for an individual observation rather than as presenting grouped sets of data.

2. Tending to interpret histograms as two-variable scatterplots or as time sequence plots.

3. Tending to look at the vertical axes and compare differences in the heights of the bars when comparing the variation of two histograms.

4. Tending to think deterministically when interpreting a distribution in real-world contexts.

The purpose of Koparan's (2014) study was to define teacher views about the difficulties involved in learning and teaching with respect to middle school statistics subjects. To serve this aim, a number of interviews were conducted with 10 middle school mathematics teachers in the 2011-2012 school year in the province of Trabzon. Among the qualitative descriptive research methods, the semi-structured interview technique was chosen for application in the research. In accordance with the aim of this study, the researcher examined and analyzed the teachers' opinions about the subjects of statistics, and grouped and evaluated responses from the teachers. The teachers regarded that the subjects of statistics in every grade of middle school were taught gradually as a positive occurrence, though some difficulties were experienced in the teaching of this subject. The findings presented in eight themes: context, sample, data representation, central tendency, dispersion measurement, probability, variance, and other difficulties.

Elmaneay (2016) found that third female students in their preparatory year had difficulties with statistics and probabilities. The study found that the correct answer ratio of eight questions (multiple choice) out of 20 questions did not reach $25 \%$ and that the correct answer ratio of four questions (right and wrong) out of eight questions did not reach $25 \%$. In addition, the correct answer ratio of nine questions (problem-solving) out of 12 questions did not reach $25 \%$. Moreover, the study found a number of learning difficulties among students, and reasons for these difficulties. This study presented a proposal for the treatment of educational difficulties that students faced.

\subsection{The Problem of the Study}

It is clear from the above that students face some difficulties during the learning of mathematics, and that these difficulties manifest themselves in each branch, as well as in the field of statistics and probability. The researcher 
in the Department of Basic Sciences in CFY at KSU conducted many interviews with students and faculty members, as well as determined and analyzed the results of student tests in a statistics and probability course. The researcher found that students faced with academic difficulties of learning a statistics and probability course. Therefore, the researcher sought to identify these academic difficulties so that the instructors can handle them correctly and accurately.

\subsection{Study Questions}

The present study attempts to answer the following questions:

1. What are students' difficulties in learning a statistics and probability course?

2. Are there statistically significant differences in students' academic difficulties in learning the statistics and probability course due to the type of instructor (male, female), years of experience in the CFY (less than 5 years, more than or equal to 5 years), and specialization (statistics, mathematics)?

\subsection{Importance of the Study}

This study deals with psychological and educational issues that are of great importance at the beginning of the university stage. The determination of the level of academic difficulties in learning statistics and probability may contribute to the development of plans and decision-making, and to the identification of appropriate solutions to reduce these academic difficulties and develop knowledge among students, as well as provide teachers with a great deal of depth in the education process.

\subsection{Limitations of this Study}

- $\quad$ The study was limited to the CFY at KSU in the second semester, 1438-1439 / 2017-2018.

- The study was limited to the statistics and probability course, which the Humanities track students in the CFY at KSU taught it.

- The study was limited to faculty members of statistics and probability (male, female) in the CFY at KSU.

\subsection{Study Approach}

The present study aims to collect data from faculty members on a range of academic difficulties in learning a statistics and probability that Humanities track students' experience, then to analyze and interpret them, extract the results, and write the recommendations. Therefore, the researcher has used a descriptive, analytical approach.

\subsection{Study Terms}

- Learning disabilities are obstacles that prevent at least $25 \%$ of students from reaching the correct solution to questions in the statistics and probability course from the point of view of the instructor. Such students do not have any kind of physical, sensory, visual, or mental disability.

- The statistics and probability course is the syllabus of the principles of Statistics and Probability (Stat 102), taught by Humanities track students in the Department of Basic Science in the CFY at KSU.

- Humanities track students are all students who study the literary material in the secondary stage and who are new in the university.

- Instructors are faculty members who teach the statistics and probability course (Stat102) for Humanities track students in the CFY at KSU.

\section{Method and Procedures}

\subsection{Population and the Study Sample}

The community of this study consisted of basic science department instructors in the CFY at KSU. The sample comprised 24 male and female instructors, as shown in the following table.

Table (1): The study sample

\begin{tabular}{|c|c|c|c|c|c|}
\hline \multirow{2}{*}{ Type } & \multicolumn{2}{|c|}{ Experience } & \multicolumn{2}{c|}{ Specialization } & \\
\cline { 2 - 6 } & Less than 5 & Greater than or equal to 5 & Stat & Math & Sum \\
\hline Male & 8 & 5 & 9 & 4 & 13 \\
\hline Female & 6 & 5 & 9 & 2 & 11 \\
\hline Sum & 14 & 10 & 18 & 6 & 24 \\
\hline
\end{tabular}

\subsection{The Study Tools}

\section{Difficulties Questionnaire}

After reviewing the educational literature and previous studies in the field regarding difficulties in the learning of mathematics and statistics, the researcher conducted several interviews with faculty members who were teaching the statistics and probability course for Humanities track students, or who had taught this course previously in 
order to accurately identify academic difficulties in learning statistics and probability, In addition, several student test papers were reviewed to identify students' errors. Then, the researcher prepared a 39-item questionnaire to determine the academic difficulties that students experienced in learning statistics and probability, with a score (15), it was from "never approved" to "fully approved". To verify the validity of the questionnaire, the researcher presented the questionnaire to a group of faculty members who specialized in curricula and teaching methods, mathematics, statistics, and measurement and evaluation. Required modifications were then made. To verify the stability of the questionnaire, the researcher used the Alpha Cronbach equation. The stability coefficient was 0.763 , which was good and acceptable.

The researcher used the following table to determine the level of difficulty from the point of view of the researcher, after reviewing previous studies on this subject.

Table (2): The levels of assessment

\begin{tabular}{c|c}
\hline Average & Difficulty's Level \\
\hline Less than $10 \%$ & Not \\
$10 \%-25 \%$ & Low \\
$25 \%-50 \%$ & Medium \\
$50 \%-75 \%$ & High \\
More than $75 \%$ & Very High \\
\hline
\end{tabular}

\section{Discuss the Results and Their Interpretation}

\section{- The first question:}

What are students' academic difficulties in learning a statistics and probability course?

To answer this question, averages, percentages, and levels were calculated, as illustrated in the following table. Table (3): Averages, percentages, and levels of students' academic difficulties

\begin{tabular}{|c|c|c|c|c|c|}
\hline Item & $N$. & Mean & S.D. & $\%$ & Level \\
\hline $\begin{array}{l}\text { 1. Distinguish between continuous and discrete quantitative } \\
\text { variables. }\end{array}$ & 24 & 2.88 & 0.741 & 57.60 & High \\
\hline 2. Understand and save definitions for the following chapters. & 24 & 3.17 & 0.868 & 63.40 & High \\
\hline $\begin{array}{l}\text { 3. Understand the difference between practical boundaries and } \\
\text { actual boundaries when solving questions. }\end{array}$ & 24 & 3.38 & 0.970 & 67.60 & High \\
\hline 4. Calculate the number of groups $(\mathrm{K})$. & 24 & 3.04 & 1.122 & 60.80 & High \\
\hline 5. Calculate the class capacity (C). & 24 & 3.08 & 1.018 & 61.60 & High \\
\hline 6. Create the frequency distribution table. & 24 & 3.33 & 0.917 & 66.60 & High \\
\hline $\begin{array}{l}\text { 7. Distinguish between the frequency curve, frequency polygon, and } \\
\text { ascending cumulative frequency polygon. }\end{array}$ & 24 & 3.42 & 0.717 & 68.40 & High \\
\hline $\begin{array}{l}\text { 8. Recognize the indication of statistical graphs (symmetry, } \\
\text { skewness, sputtering, and flatting frequency distribution). }\end{array}$ & 24 & 3.38 & 1.245 & 67.60 & High \\
\hline $\begin{array}{l}\text { 9. Distinguish between data rules and frequency distribution table } \\
\text { rules. }\end{array}$ & 24 & 3.58 & 1.100 & 71.60 & High \\
\hline 10. Calculate the medium of a frequency distribution table. & 24 & 3.83 & 0.963 & 76.60 & $\begin{array}{l}\text { Very } \\
\text { High }\end{array}$ \\
\hline 11. Calculate the mode of a frequency distribution table. & 24 & 3.67 & 0.702 & 73.40 & High \\
\hline 12. Realize the relationship between the mean, median, and mode. & 24 & 3.45 & 1.141 & 69.00 & High \\
\hline 13. Realize the concept of the rank in quartiles $q_{r}$ and percentiles $p_{r}$. & 24 & 2.96 & 1.083 & 59.20 & High \\
\hline $\begin{array}{l}\text { 14. Recognize the indication of symbols when calculating the quartile } \\
\text { or percentile. }\end{array}$ & 24 & 3.13 & 0.900 & 62.60 & High \\
\hline 15. Realize that $Q_{1}=P_{25}, \tilde{x}=Q_{2}=P_{50}, Q_{3}=P_{75}$. & 24 & 2.71 & 1.083 & 54.20 & High \\
\hline 16. The box plot representation of data. & 24 & 3.83 & 1.204 & 76.60 & $\begin{array}{l}\text { Very } \\
\text { High }\end{array}$ \\
\hline 17. Identify and represent extreme values. & 24 & 3.67 & 1.129 & 73.40 & High \\
\hline $\begin{array}{l}\text { 18. Calculate a variance (application of the rule and indication of } \\
\text { symbols). }\end{array}$ & 24 & 3.63 & 1.096 & 72.60 & High \\
\hline 19. Recognize the concept of Z-Score. & 24 & 3.38 & 1.096 & 67.60 & High \\
\hline $\begin{array}{l}\text { 20. Recognize the indication of symbols of Pearson's Coefficient of } \\
\text { correlation. }\end{array}$ & 24 & 3.50 & 1.216 & 70.00 & High \\
\hline 21. Explain the value of the correlation coefficient. & 24 & 2.83 & 0.868 & 56.60 & High \\
\hline 22. Calculate the coefficient of $X(b)$ in the linear regression equation. & 24 & 3.67 & 1.204 & 73.40 & High \\
\hline 23. Estimate the value of $\hat{Y}$ wh & 24 & 3.17 & 0.868 & 63.40 & High \\
\hline
\end{tabular}




\begin{tabular}{|c|c|c|c|c|c|}
\hline Item & $N$ & Mean & S.D. & $\%$ & Level \\
\hline $\begin{array}{l}\text { 24. Distinguish between permutations and combinations in word } \\
\text { problems. }\end{array}$ & 24 & 4.25 & 0.989 & 85.00 & $\begin{array}{l}\text { Very } \\
\text { High }\end{array}$ \\
\hline 25. Calculate permutations. & 24 & 3.75 & 1.294 & 75.00 & $\begin{array}{l}\text { Very } \\
\text { High } \\
\end{array}$ \\
\hline 26. Calculate combinations. & 24 & 3.83 & 1.167 & 76.60 & $\begin{array}{l}\text { Very } \\
\text { High }\end{array}$ \\
\hline 27. Understand word problems and interpret them. & 24 & 4.21 & 0.932 & 84.20 & $\begin{array}{l}\text { Very } \\
\text { High }\end{array}$ \\
\hline 28. Find $2^{\Omega}$ for a randomized experiment. & 24 & 3.54 & 0.884 & 70.80 & High \\
\hline $\begin{array}{l}\text { 29. Recognize that the probability is a function, domain is } 2^{\Omega} \text {, } \\
\text { codomain is } \mathrm{R} \text {, and range is part of } \mathrm{R} \text {. }\end{array}$ & 24 & 3.79 & 1.021 & 75.80 & $\begin{array}{l}\text { Very } \\
\text { High }\end{array}$ \\
\hline 30. Calculate the probability of an event. & 24 & 3.63 & 1.173 & 72.60 & High \\
\hline 31. Interference between different probability laws. & 24 & 4.13 & 0.992 & 82.60 & $\begin{array}{l}\text { Very } \\
\text { High }\end{array}$ \\
\hline 32. Distinguish between total probability formula and Bays' formula. & 24 & 3.79 & 1.021 & 75.80 & $\begin{array}{l}\text { Very } \\
\text { High }\end{array}$ \\
\hline $\begin{array}{l}\text { 33. Distinguish between independence and mutually exclusive } \\
\text { events. }\end{array}$ & 24 & 3.91 & 1.065 & 78.20 & $\begin{array}{l}\text { Very } \\
\text { High }\end{array}$ \\
\hline $\begin{array}{l}\text { 34. Realize that the variable is a function } \Omega \rightarrow \mathbb{R} \text {, and the image of } \\
\Omega \text { is } \Omega^{*} \text {. }\end{array}$ & 24 & 4.29 & 0.908 & 85.80 & $\begin{array}{l}\text { Very } \\
\text { High }\end{array}$ \\
\hline 35. Determine whether the $\mathrm{X}$ variable is a random variable or not. & 24 & 4.17 & 0.917 & 83.40 & $\begin{array}{l}\text { Very } \\
\text { High }\end{array}$ \\
\hline 36. Distinguish between $2^{\Omega}$ and $2^{\Omega^{*}}$ & 24 & 3.58 & 1.018 & 71.60 & High \\
\hline 37. Calculate the probability that the random variable takes any value. & 24 & 4.04 & 0.908 & 80.80 & $\begin{array}{l}\text { Very } \\
\text { High }\end{array}$ \\
\hline 38. Represent the random variable in a table. & 24 & 3.17 & 1.090 & 63.40 & High \\
\hline 39. Understand the concept of a binomial random variable. & 24 & 4.00 & 1.142 & 80.00 & $\begin{array}{l}\text { Very } \\
\text { High }\end{array}$ \\
\hline
\end{tabular}

It is clear from the above table that, from the point of view of the instructors, students experienced more academic difficulties ranging in the "high" and "very high" levels in all items on the students' academic difficulties questionnaire. Ten academic difficulties reached a "very high" level: 10, 16, 24, 27, 29, 31, 34, 35, 37, and 39 . Among these, the highest difficulty was item 34 "Realize that the variable is a function $\Omega \rightarrow \mathbb{R}$, and the image of $\Omega$ is $\Omega^{*}$ "; the proportion of this difficulty exceeded $85.80 \%$. Number 24 "Distinguish between permutations and combinations in word problems" whose rate of difficulty was $85 \%$ followed it. Difficulty number 27 came in third place with a percentage of $84.20 \%$; it stated, "Understand word problems and interpret them", it followed by difficulty number 31 , which stated, "Interference between different probability laws," and had a percentage of $82.60 \%$. Next, the difficulty number 37 , which stated, "Calculate the probability that the random variable takes any value" and had a percentage of $80.80 \%$. The difficulty number 39 came in seventh place; it stated, "Understand the concept of binomial random variable" and had a percentage of $80 \%$. Three academic difficulties $(10,16$, and 29) came at the end of these ten academic difficulties, which states "Distinguish between data rules and frequency distribution table rules, the box plot representation of data and Recognize that the probability is a function, the domain is $2^{\Omega}$, codomain is $\mathrm{R}$, and range is part of $\mathrm{R} "$.

Four of the ten previous academic difficulties were in the random variable lesson; these were 34, 35, 37, and 39. Two of them were in the probability lesson; these were 29 and 31 . Two of them were in the permutations and combinations lesson; these were 24 and 27. One of them (16) was in the box plot lesson, while one of them (10) was in the frequency distribution table lesson.

While the remainder of the academic difficulties occurred at a high level, there were no academic difficulties at the "medium" or "low" level. The results in the previous table show that most of the previous academic difficulties that occurred at the "very high" level arose in later lessons that showed permutation, combination, probability, and the random variable. This indicates that these lessons were very difficult for students of the Humanities track. As the results show, the academic difficulties mentioned in the questionnaire were found among students and located at the "very high" and "high" levels. The results indicate the presence of accuracy and careful analysis in preparation of the questionnaire and that students were already experiencing all the academic difficulties of the questionnaire.

The results also show that item 15 "Calculate the class capacity (C)"gave the least difficulty to students, with 
a percentage of $54.20 \%$. It was followed by item 21 "Explain the value of correlation coefficient", with a percentage of $56.60 \%$, and item 1 "Distinguish between continuous and discrete quantitative variables", with a percentage of $57.60 \%$. However, these three academic difficulties have least degree, but they also occurred at a high level.

These academic difficulties may be Due to the weakness of the students' mathematical background; because they had not studied mathematics at secondary school and were not interested in studying mathematics because they would not be taking any mathematics course in the next academic year. The students also have some factors that led to these academic difficulties such as their unwillingness and a lack of their motivation to learn statistics, as well as a cumulative weakness among them in all the mathematical branches. These academic difficulties may also be due to the instructors who used traditional teaching methods and disregarded individual differences among students, or to the nature of a statistics and probability textbook, Which may have a lack of connection between the material and real life, a lack of enrichment materials that clarified the concepts, relationships, and skills, a lack of examples and a lack of graphics and illustrations.

The results of this study partially agree with the results of Koparan (2014) and Elmaneay (2016) in that it found a number of difficulties that students experience in learning statistics and probability. It differs from these two studies in terms of the type, nature, and level of each of these difficulties.

- The second question:

Are there statistically significant differences in student's academic difficulties in learning a statistics and probability course due to the type of instructor (male, female), years of experience in the CFY (less than 5 years, more than or equal to 5 years), and specialization (statistics, mathematics)?

To answer this question, a T-test for the two independent groups was calculated, as illustrated in the following table:

Table (4). T test for the two independent groups

\begin{tabular}{|c|c|c|c|c|c|c|}
\hline Section & Gender & $N$ & Mean & S.D. & "T" Value & Sig. \\
\hline \multirow{2}{*}{ Type } & Male & 13 & 3.71 & 0.80 & \multirow{2}{*}{1.076} & \multirow{2}{*}{0.294} \\
\hline & Female & 11 & 3.38 & 0.70 & & \\
\hline \multirow{2}{*}{ Experience } & Less than 5 & 14 & 3.46 & 0.78 & \multirow{2}{*}{0.630} & \multirow{2}{*}{0.535} \\
\hline & More than or equal to 5 & 10 & 3.67 & 0.76 & & \\
\hline \multirow[t]{2}{*}{ Specialization } & Statistics & 18 & 3.58 & 0.78 & \multirow{2}{*}{0.183} & \multirow{2}{*}{0.856} \\
\hline & Mathematics & 6 & 3.51 & 0.78 & & \\
\hline
\end{tabular}

The statistical values shown in Table 4 indicate that no statistically significant differences exist in terms of the level of students' academic difficulties in learning statistics and probability, due to the type of instructor (male or female), the instructor' experience in the CFY (less than 5 years or more than or equal to 5 years), and the instructor's specialization (statistics or mathematics). This may be due to the students in the humanities track did not study mathematics or statistics at the secondary level before entering the first year of university and they have a lower level of mathematics or statistics knowledge. This lower level leads to the absence of statistically significant differences between instructors' view, where all the different instructors consider that all students have the same academic difficulties.

The results of the differences also indicate that there are significant differences between male and female instructors in their view about students' academic difficulties in learning statistics and probability, where male instructors see that the students suffer from difficulties, 13, 21, 23, 28, and 32 more than female do, so the male and female instructors agree on nine of the previous ten difficulties, except the difficulty number 29, they differed. There are statistically significant differences between instructors with experience less than five years and more than five years' experience in difficulties 1 and 22, where the instructors with more than five years' experience see that the students suffer from these difficulties more than other instructors do, therefore, these instructors agree on the previous 10 difficulties. There are statistically significant differences between statistics and Mathematics instructors, where statistics instructors see that the students suffer from difficulties, 3 and 36 compared to mathematics instructors, therefore, these instructors agree on the previous 10 difficulties too.

\section{Conclusion and Recommendations}

Previous results showed that, in general, students of the Humanities track face a large number of academic difficulties in learning statistics and probability, due to the weakness of their mathematical and statistical background, and that these academic difficulties are concentrated in the lessons of permutation, combination, probability, and random variable. The results indicated that all the academic difficulties surveyed by instructors occurred at the "high" or "very high" level and that no difficulty was located at the medium or low levels. In light of these results, the researcher recommends the following:

- Modify and reduce the curriculum to focus on the most important topics that benefit students in their future studies.

- $\quad$ Achieve quality and not quantity when teaching statistics and probability. 
- Consider the fact that students are in the Humanities track and that their mathematical and statistical background is weak when one is writing, developing, or teaching from a statistics and probability textbook.

- Provide sufficient time for instructors to explain the difficult lessons, as well as to remedy these academic difficulties.

- Conducting a number of workshops for instructors on the academic difficulties that raised in this study to show them the correct methods to deal and remedy these academic difficulties.

- Conduct many studies in the field of learning disabilities in other courses and among other samples of students.

\section{References}

Acharya, R. B. (2017). Factors Affecting Difficulties in Learning Mathematics by Mathematics Learners, International Journal of Elementary Education; 6(2): 8-15.

Alshakhs, A. A. (2006). Children with Special Needs and Methods of Care, Cairo, El Fatah Library.

Asha, I., Beqe'e N. \& Alabsi M. (2014). Levels of Difficulties to Learn Mathematics from the Perspective of Practicum Students: Students' Suggestions and Solutions (College of Educational Sciences and Arts UNRWA), journal of Taiba University for Educational Sciences, 9(2), 215-229.

Batanero, C., Burrill, G. \& Reading, C. (2011). Teaching Statistics in School-Mathematics- Challenges for Teaching and Teacher Education: A Joint ICMI/IASE Study, DOI 10.1007/978-94-007-1131-0, Springer Science + Business Media B.V. 407- 418.

Batanero, C., Burrill, G., Reading, C., \& Rossman, A. (2008). Joint ICMI/IASE Study: Teaching Statistics in School Mathematics. Challenges for Teaching and Teacher Education. Proceedings of the ICMI Study 18 and 2008 IASE Round Table Conference. Monterrey, Mexico: International Commission on Mathematical Instruction and International Association for Statistics Education. Online: www.stat.auckland.ac.nz/ iase/publications

Batanero, C., Godino, J. D., Vallecillos, A., Green, D.R. \& Holmes, P. (1994). Errors and difficulties in understanding elementary statistical concepts, International Journal of Mathematics Education in Science and Technology, 25(4), 527-547.

Bryant, D. P., Bryant, B. R., Gersten, R., Scammacca, N. \& Chavez, M. M. (2008). Mathematics Intervention for First- and Second-Grade Students with Mathematics Difficulties, the Effects of Tier 2 Intervention Delivered As Booster Lessons, Remedial and Special Education, 29 (1), 20-32

Bryant, B. R., Bryant, D. P., Kethley, C., Kim, S. A., Pool, C. \& Seo Y. (2008). Preventing Mathematics Difficulties in the Primary Grades: The Critical Features of Instruction in Textbooks as Part of the Equation, Learning Disability Quarterly, Volume 31, winter 2008, 21-35

Elmaneay, M. R. (2016). Difficulties in learning the content of the statistics and the probability of the third-grade students at preparatory school, and a proposed proposal for treatment them from the point of view of specialists, Master Thesis published, Faculty of Education, Qassim University, Saudi Arabia, 1-136.

Grehan, M., O'Shea A. \& Bhai C. M. (2010). How do students deal with difficulties in mathematics?, CETLMSOR Conference 2010, 34-38

Holm, M. E., Aunio, P., Björn, P. M., Klenberg, L., Korhonen, J., \& Hannula, M. S. (2017). ExecutIve Functions and Mathematics Difficulties 1, Behavioral Executive Functions among Adolescents with Mathematics Difficulties, Journal of Learning Disabilities, 1-11.

Hudson, S, Kadan, S, Lavin, K. \& Vasquez, T. (2010). Improving Basic Math Skills Using Technology" (ED512698), 1-75.

Jupri, A. \& Drijvers, P. (2016). Student Difficulties in Mathematizing Word Problems in Algebra, Eurasia Journal of Mathematics, Science \& Technology Education, 12(9), 2481-2502 doi: 10.12973/eurasia.2016.1299a.

Koparan, T. (2015). Difficulties in learning and teaching statistics: teacher views, International Journal of mathematical education in science and technology, 46 (1), 94- 104.

Lee, C. \& Mavrotheris M. M. (2003). Some Difficulties of Learning Histogram in Introductory Statistics, Conference: 2003 Joint Statistical Meetings - Section on Statistical Education, At San Francisco, California, Volume: Proceedings of the 2003 Joint Statistical Meeting, 2326- 2333

Mendoza, L. (1999). Empirical research in understanding probability. In R. Kapadia \& M. Porovcnik (Eds.), Chance Encounters: Probability in education, Kluwer academia publishers, Dordrecht, p 356.

Pepper, R. E., Chasteen S. V., Pollock S. J. \& Perkins K. K. (2012). Observations on student difficulties with mathematics in upper-division electricity and magnetism, The American Physical Society, 8(1), 010111(15), $1-15$

Tall, D. \& Razali, M. R. (1993). Diagnosing Students' Difficulties in Learning Mathematics, International Journal of Mathematical Education in Science and Technology, 24:2, 209-222

Tambychik, T. \& Meera, T. S. M. (2010). Students' Difficulties in Mathematics Problem-Solving: What do they 
Say?, International Conference on Mathematics Education Research, Procedia Social and Behavioral Sciences, Published by Elsevier Ltd., doi:10.1016/j, 8, 142-151.

Tishkovskaya, S. Lancaster, G. A. (2012). Statistical Education in the 21st Century: a Review of Challenges, Teaching Innovations and Strategies for Reform, Journal of Statistics Education, Volume 20, 1-56.

Vukovic, R. K. (2012). Mathematics Difficulty With and Without Reading Difficulty: Findings and Implications From a Four-Year Longitudinal Study, Council for Exceptional Children, Vol. 78, No. 3, 280-300.

Zachariades, T., Christou, C. \& Papageorgiou, E. (2001). The difficulties and reasoning of undergraduate mathematics students in the identification of functions, Department of Mathematics and Statistics of the University of Cyprus, online: http://users.math.uoc.gr/ ictm2/Proceedings/pap353.pdf 